\title{
Ecosystem Services in the Management System of Ecological Safety of Territorial Units
}

\author{
Mykola Prykhodko* \\ Department of Geodesy and Land \\ Management \\ Ivano-Frankivsk National Technical \\ University of Oil and Gas \\ Ivano-Frankivsk, Ukraine \\ prihodkon@ukr.net \\ Ivanna Melnychuk \\ Department of Applied Economics \\ Ivano-Frankivsk National Technical \\ University of Oil and Gas \\ Ivano-Frankivsk, Ukraine \\ ivankamelnychuk84@gmail.com
}

\author{
Nataliia Havadzyn \\ Department of Applied Economics \\ Ivano-Frankivsk National Technical \\ University of Oil and Gas \\ Ivano-Frankivsk, Ukraine \\ n_havadzyn@ukr.net
}

\author{
Mariia Berlous \\ Department of Management and \\ Administration \\ Ivano-Frankivsk National Technical \\ University of Oil and Gas \\ Ivano-Frankivsk, Ukraine \\ masherydebby@gmail.com
}

\author{
Liliana Horal \\ Department of Finance \\ Ivano-Frankivsk National Technical \\ University of Oil and Gas \\ Ivano-Frankivsk, Ukraine \\ https://orcid.org/0000-0001-6066-5619
}

\begin{abstract}
Preservation and restoration of the natural environment and ensuring environmentally safe functioning of ecosystems are the priority conditions for implementation of the dominant social paradigm, which is development in harmony with nature. The article describes the essence of management system of ecological safety of territorial units as a set of actions and processes aimed at planning and constructing optimum options of spatial-temporal structuralfunctional organisation of ecosystems, restoration and increase of their ecological potential and stability, prevention of occurrence and development of ecological risks. Structure blocks of the system are environmental audit, environmental design (planning), environmental monitoring, databases and data banks with the use of GIS technologies. Implementation of the ecosystem services concept has an important role in the management system of ecological safety of territorial units. It is based on the need of co-evolution development of ecological and economic components. Monetary evaluation of the ecosystem services, development and introduction of payment mechanisms for these services will allow implementing programs (measures) for ensuring environmentally safe functioning of ecosystems within the territorial units.
\end{abstract}

Keywords-ecosystem services, ecosystem, management, ecological safety, planning

\section{RELEVANCE OF THE RESEARCH}

Preservation and restoration of the natural environment and ensuring environmentally safe functioning of ecosystems are the priority conditions for implementation of the dominant social paradigm, which is development in harmony with nature. There is a need to search for a compromise between social and economic needs of the humanity and capabilities of the biosphere for their satisfaction $[1,2]$.
With modern production and consumption models the natural resources are used faster than restored. Capabilities of the natural environment for resistance to these processes are near exhaustion. Development in harmony with nature is impossible without transfer to the production and consumption models ensuring non-exhausting use of natural resources and ecological safety of territorial units. Presence of the ecological risks and the need of ensuring environmentally safe functioning of ecosystems determine the relevance and importance of development and introduction of the management system of ecological safety of territorial units.

At the present stage of social development, the most efficient tools of effective use, preservation and restoration of ecosystem functions are those based on the economic interest. On the other hand, the modern economics does not fully take into account economic contributions of ecosystem values, which is largely explained by the lack of coherent scientific approach to determining their essence and meaning and methodological tools for their economic valuation [3]. Due to this a need arises for corresponding scientific researches and inclusion of the ecosystem services in activities of economic entities.

\section{Purpose OF THE ARTICLE}

To develop the structure of management system of ecological safety of territorial units and show the role of ecosystem services in it.

\section{ANALYSIS OF PREVIOUS RESEARCHES}

Adverse man-made changes of the natural environment, disharmony between the pace of use of natural resources and their restoration became the objective prerequisite for the need to apply scientific methods of management in the area of use and restoration of natural resources and ecological safety of territorial units. Available management systems in Ukraine are characterised by departmental fragmentation, structural complexity and functional and territorial inconformity of its constituent elements. Under 
such conditions it is necessary to develop a strategy and principles for management of ecological safety of territorial units to ensure coordinated development of natural and business subsystems within integral "nature - society" system.

Two types of territorial units management, namely "hard" and "soft" are the most common. "Hard" management provides for interference in natural processes, their "correction" by drastic alterations of natural mechanisms and systems [4]. Territorial units management requires understanding of ecosystem organisation mechanisms within their limits not only as individual territorial entities (as considered in the context of this article), but as a certain link of ecological chain within corresponding earth surface area. This particular aspect is often absent in the "hard" management making it destructive.

"Soft" management is indirect influence on the ecosystems, generally by natural self-regulatory mechanisms, however sometimes with design engineering of these mechanisms. It is aimed at restoration of previous natural productivity of the ecosystems or its increase through targeted measures based on the use of objective natural development laws that allows directing natural chain reactions to the "soft" option [4]. This management also has some downsides, but they are not catastrophic for the ecosystems, as ecosystems are able to eliminate adverse effects via self-regulatory mechanisms.

We can conclude from the above that the management is a targeted influence of a subject (human) on the ecosystems through planning and making corresponding decisions on maintaining the ecosystems in a certain state via managerial impact for achieving a target goal, a targeted function of organisation, which goal is preservation of invariant structure and general direction of the ecosystem development. The management lies in selection of optimum options of ecosystems territorial organisation planning, which ensure their stable functioning and development at all levels of spatial-temporal and functional organisation; it is a system of actions aimed at achieving a certain quality level of the environment ensuring normal functioning of the ecosystems, their environment and resource restoration properties.

The most rational management is in the direction of natural self-regulatory mechanisms restoration, i.e. biotic regulation [5]. It should be aimed at restoring the natural ecological potential [6] of ecosystems or its increase through implementation of targeted system of measures based on the use of objective natural development laws that allows directing natural chain reactions to the option which is favourable for the ecosystems, economy and human life.

The management belongs to the process of conscious anthropogenic impact on the ecosystems in order to maintain, adjust or alter the natural mechanisms. That is to say, there are two processes: existing condition of the ecosystems with available spontaneously formed management mechanisms and planned state of these ecosystems with a certain share of anthropogenic management. The ecosystem becomes controlled when among all impacts on it there is the impact which provides an opportunity to achieve the determined goal.

The management process has dual nature: direct management of certain territorial system and management of its environment. At the same time, the very environment has control and correction functions in spontaneous functioning mode of territorial systems [7, 8]. This management is understood as systematic transformation of ecosystemic differentiated environment in the interest of human, but without destruction of biotic regulation mechanisms. Efficiency of managerial decisions is determined via the most integral territorial systems characteristic - their stability [9].

\section{STATEMENT OF BASIC MATERIALS}

The management system of ecological safety of territorial units is a complex and comprehensive problem, which solution is aimed at ensuring safe functioning of the ecosystems that is determined by all processes accompanying their existence (vital activity, productivity, exchange and flows of substances). Ensuring absolute ecological safety (zero risk principle) requires significant material costs. Due to this the management system of ecological safety of the ecosystems is based on acceptable risk principle. Ecological safety level indicators are ecosystem stability and ecological potential indices and health level of the population $[9,10]$.

Ecological safety of territorial unit is determined as condition of the ecosystem within its boundaries, which ensures maintaining ecological risks at "acceptable risk" level, restoration of primary ecological potential of ecosystems, elimination (minimisation) of threats both for ecosystem components and for vital activities and health of people.

The territorial units should be a result of efficient management and planning, their constant improvement for construction of stable and environmentally safe ecosystems within their boundaries. According to the systems theory, the more complex ecosystem structure is, the more resistant it is to environmental effects.

Creating conditions preventing negative impact of anthropogenic activities on the ecosystems is implemented through well-balanced use of resources, planning and construction, as well as optimisation of the ecosystems [11].

The main task in substantiating the measures for management of ecological safety of territorial units is solving a problem of ensuring integrity and optimal structure of ecosystems within their boundaries. The ecosystems structure optimisation is based on the principle of production and economic activities conformity to the specific features of ecosystems. These specific features determine certain restrictions (limits) for reclamation of ecosystems and types of their economic use.

On the basis of the foregoing we determine the management system of ecological safety of territorial units as targeted activities (set of actions, processes and measures) aimed at planning and constructing optimum options of spatial-temporal structural-functional organisation of ecosystems within their boundaries, restoration and increase of ecological potential and stability of ecosystems, prevention of occurrence and development of ecological risks, maintenance of ecological and economical balance and implementation of ecosystem strategies. Herewith the ecosystem strategy is a set of mutually adapted features, qualities and properties of the ecosystem, which ensure its adaptation to changing environmental conditions and are aimed at implementation of individual and group 
evolution program [12]. The main essence of the management system of ecological safety of territorial units lies in the fact that the management cannot be efficient, if it is implemented by branch-wise principle within individual ecosystems and their components without taking into account functional interrelationships both between ecosystem components and the ecosystems. One of the highpriority tasks in the management system of ecological safety of territorial units is determining the future state of management objects. This determines obligatory implementation of planning function on the management system.

The management which ensures the ecological safety of territorial units should be carried out keeping in mind the necessity of maximum preservation and restoration of the natural ecosystems and formation of the anthropogenically modified ecosystems (agroecosystems) taking into account parity of interests of the biosphere and society. The parity is achieved through scientifically grounded structuralfunctional organisation of the territorial units and optimum ratio of natural and anthropogenically modified ecosystems.

The management of ecological safety of territorial units shall be carried out subject to the following principles:

1) principle of unconditional priority of safety;

2) consideration of limitation of natural and resource and ecological potential;

3) timely implementation of measures;

4) forecasting of adverse effects on the basis of multivariate analysis of possible situations;

5) adaptability of the management, i.e. ability to change managerial decisions (measures) according to the change of conditions and goals of the management;

6) control (monitoring) over approaching the goal of managerial decisions.

The management system of ecological safety of territorial units should include: 1) analysis of causes of the ecological risks and their characteristic; 2) rate setting of the risks by mechanisms of their regulation (permits for maximum permissible emission and maximum permissible discharge of contaminants, formation and disposal of waste, environmentally safe resource utilisation standards); 3) preservation and restoration of the natural ecosystems; 4) balanced use of resources on the basis of achieving a balance between the economic development and natural resource potential; 5) substantiation of measures (strategies) for minimising ecological risks and ensuring the ecologically safe functioning of ecosystems (natural, anthropogenically modified, anthropogenic, technogenic) within the territorial unit; 6) integration of geospatial data in GIS format to provide the users with information.

The management system of ecological safety of territorial units has hierarchical level of structure, information flows and the system of direct and inverse links and is based on the statement that changes in the system are conditioned by these links. Achieving the final result, which is environmentally safe functioning of ecosystems within the territorial unit, is a function of parameters of individual system blocks pursuant to which the managerial decisions should be substantiated and made. The management system of ecological safety of territorial units (Figure. 1) consists of the following blocks:

1) environmental audit, which includes identification of ecosystems and characteristic of existing ecological risks, evaluation of the ecosystem services and their use;

2) environmental design aimed at planning and construction (project development) of structural-functional organisation of ecosystems within the territorial unit with substantiated managerial decisions (measures and resources) for achieving the ecological safety of territorial unit;

3 ) environmental monitoring, which task is control over the response of ecosystems to implemented projects (managerial decisions);

4) databases and data banks with the use of GIS technologies.

Implementation of the ecosystem services concept has an important role in the management system of ecological safety of territorial units. It is based on the need of coevolution development of ecological and economic components and is contained in the national policies and legislation of many countries. It became a basis for a number of international treaties and is contained in the final acts of the United Nations Conference on Sustainable Development Rio+20. The EU Biodiversity Strategy requires all EU member states to establish and evaluate ecosystems and their services at national level by 2020, as well as to integrate the obtained results in the common system of ecological and economic calculations [13]. The ecosystem approach should be introduced in territorial management in Ukraine by 2020. Ukrainian legislation in this field should be harmonized with European.

Monetary evaluation of the ecosystem services, development and introduction of payment mechanisms and use of costs for these services will allow implementing programs (measures) for ensuring environmentally safe functioning of ecosystems within the territorial units.

In classic terms the ecosystem is a N-dimensional nonranked unit uncharacteristic of territorial limitations (its size is determined by the system measure). Therefore, distinction of ecosystems at the territorial level is important for scientific substantiation and implementation of the ecosystem services concept. European ecosystem classification EUNIS (European Nature Information System) takes habitat as the smallest unit of such ecosystems that is close to ecotope. This is flora and fauna forming biotic environment together with abiotic factors and interacting in a specific area [14].

EUNIS ecosystem classification absorbed positive features of various classifications (Emerald, NATURA 2000, CORINE, Palearctic Habitats) and is based on evaluation of similar ecotopes. It has hierarchical structure and includes 11 main types, in which levels of II-VIII orders are distinguished.

The most common definition of the ecosystem services in scientific literature is as follows: the ecosystem services are benefits and values obtained from the ecosystems, as well as all list of material, energy and information flows created by natural capital reserves, which provide for welfare of the community combined with physical, human and social capital $[15,16]$.

Currently there are three international ecosystem services classifications [18]: 1) Millennium Ecosystem Assessment (MA); 2) The Economics of Ecosystems and Biodiversity (TEEB); 3) Common International Classification of Ecosystem Services (CICES). CICES classification is based on two above-mentioned classifications, but is more targeted at recording and 
economic evaluation of the ecosystems at national, regional and local levels. These classifications are quite similar in essence and include three main categories of the ecosystem services: provisioning - provision of people with material values and resources directly used by them; regulating - various ecosystem mechanisms that regulate environment indicators directly important for human welfare; cultural non-material satisfaction of cultural, spiritual and scientific needs of people [17].

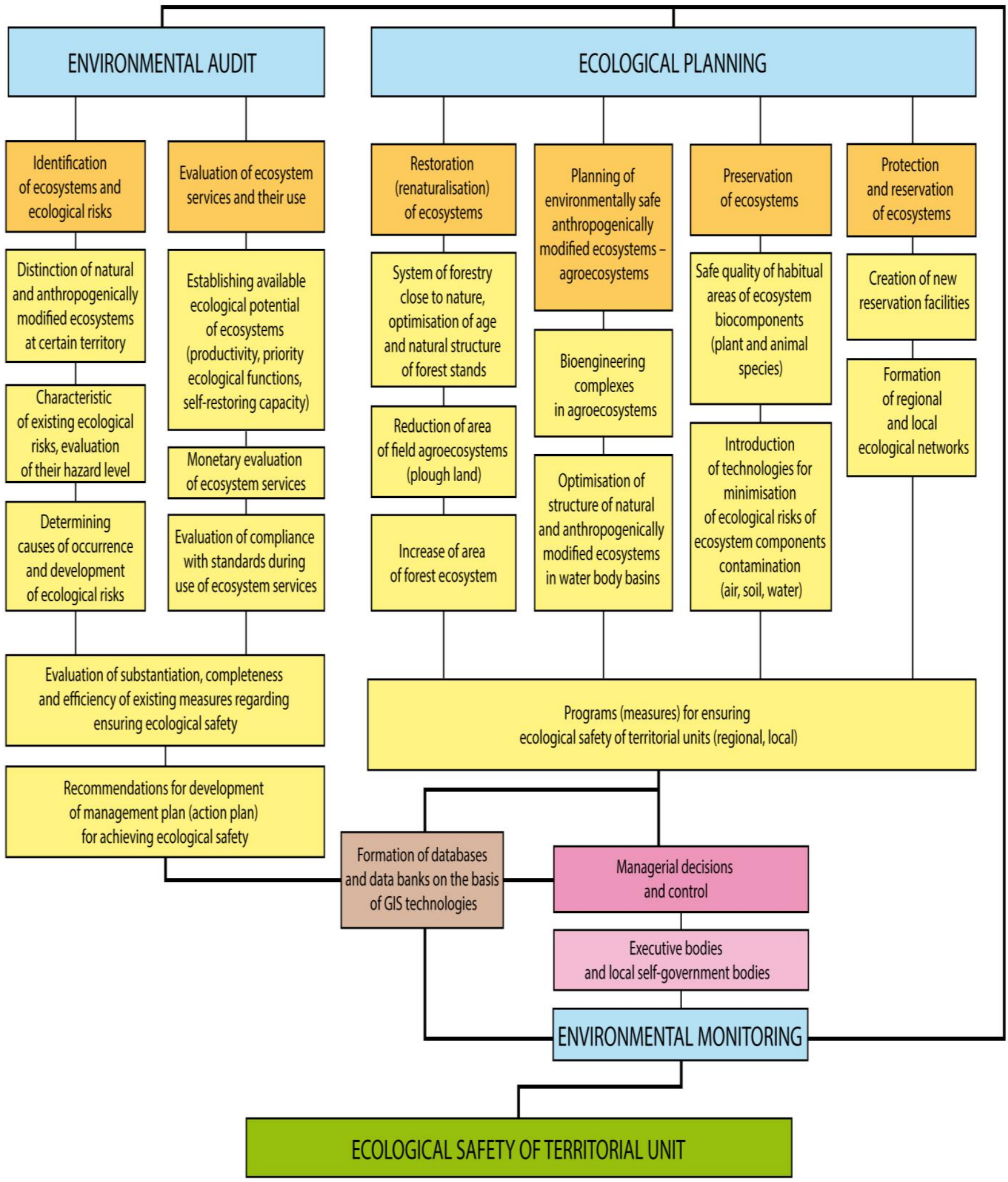

Fig. 1. Management system of ecological safety of territorial units (created by the author) 
Work on typification and coordination of the list of ecosystem services is ongoing (HainesYoung, Mishenin Ye.V) $[3,18]$.

Cost estimate of the ecosystem services depends on their comprehension and understanding. It is very problematic to acknowledge, study and evaluate all ecosystem services, as well as envisage their possible changes due to influence of human activities. Lack of this information results in undervaluation of the ecosystem services. Various methods are used for cost estimate of the ecosystem services depending on subject of estimation, stringency level of requirements to analysed data and restrictions allowed [19]. It is reasonable to apply several estimation methods in parallel to obtain more trustworthy results.

Cost estimate of the ecosystem services can be considered as efficiency of their use. Irrational use results in destructive ecological impacts on the ecosystems which are economical losses. They consist of cost value necessary for damage limitation (liquidation of forest fires, contaminated water purification, land reclamation etc.), size of lost (forgone, short-received) economic benefits during provision of the ecosystem services in disordered natural environment, as well as significant additional costs that should be incurred by a wide range of recipients, for example, due to reduction in biodiversity, soil salinization, loss of recreational territories etc. Herewith, even one-time adverse ecological environmental impacts can be in evidence during long course or increase in length of time.

Therefore, in our opinion, prevented losses can be considered as the ecosystem services efficiency. The funds that should be spent for rectification of the consequences of ecological destructions or possible accidents can be used for other purposes related to the ecosystem services development.

Further in this regard it is obvious that cost of funds in non-recurrent amount of prevented losses will accrue (increase, rise) during the time of beneficial use of the ecosystem services. Size of this accrual can be determined (evaluated) by the known formula of currency unit future value. It is an important fact that the higher the level of possible destructive impacts is, the higher cost of the ecosystem service will be. In other words, higher level of the ecological risks in the formula of future value acts as an additional rate of return on investment or in the form of premium for increased risks.

On the other hand, when determining the ecosystem service cost on certain current date it is necessary to determine the current cost of hypothetic monetary flows from its use. It can be made using currency unit current value function. But it is reasonable to use basic rate of return as a discount rate taking into account significance of the ecosystems and for risk neutralisation. On the basis of the foregoing, cost of the ecosystem services may be estimated by the formula

$$
N P V=\left[R_{e}\left(1+r_{e}\right)^{t}+\sum_{t=1}^{T}\left(\sum_{i=1}^{n} \Delta E_{t_{i}}-\left(B_{e_{t}}+I_{e_{t}}\right)\right] /\left(1+r_{5}\right)^{\mathrm{t}}-\sum_{k=0}^{K} I_{k}\left(1+r_{E}\right)^{\mathrm{k}}\right.
$$

where: NPV is net prevent value;

$R_{e}$ is ecological risk, which is a quantitative measure of destructive ecological impact occurrence on the ecosystems (forest fire, flood, soil erosion, drought) and is determined as a product of size of damages from the adverse environmental impact and likelihood of accident occurrence;

$\Delta E_{t_{i}}$ is a size of $i$ type of economic benefit from the use of ecosystem services during ecosystem exploitation;

$B_{e_{t}}$ are operating costs in $t$ period; $I_{e_{t}}$ are investment costs in $t$ period related to additional contributions for maintaining the ecosystem functioning and ecosystem services provision;

$n$ is a number of types of economic benefits from the ecosystem services provision;

$t$ is a year of obtaining $i$ economic benefit varying within $1,2,3, \ldots, T$;

$T$ is a year of expected end of the ecosystem service use; $I_{k}$ are investments related to capital investments for preservation and restoration of the ecosystem and ecosystem services provision;

$k$ is a year from the start of ecosystem service use varying within $0,1,2, \ldots, K$;

$K$ is a year of end of creating facilities for ecosystem services provision; $r_{e}$ is ecological discount rate;

$r_{b}$ is basic discount rate.

It is important to substantiate ecological and basic discount rates for proper consideration of the time factor when estimating the ecosystem services cost. Currently there are the following methods of discount rates determination: build-up method, capital assets model, dividend discount model, extraction method, arbitration model, weighed average capital cost model [20]. Analytic expression describing the build-up method is as follows

$$
r=r_{\sigma}+\sum_{i=1}^{n} r_{i}
$$

where: $r_{b}$ is basic rate of return;

$\sum_{i=1}^{n} r_{i}$ is aggregate premium for risk.

When estimating the cost of ecosystem services, it is necessary to compare its return with return of other ecosystem services with known risk level. Comparison object does not need to be risk free service asset. Any type of assets with known return and relative risk can be used as a basis for comparison. At the same time return of the ecosystem service with higher risk should exceed return of the service with lower risk, since return increase is compensation for relatively higher degree of risk.

The rate of return of so-called risk-free assets, which are long-term government bonds with a maturity of 10 and more years, is most often applied in the world practice, since this type of investment is considered as the least risky, i.e. theoretically free of default, and their rate of return is periodically published in mass media. On the average nominal yield of the long-term government bonds with a maturity of 10 years in the USA, Japan and leading European countries is about $6 \%$ adjusted for inflation [20]. In Ukraine investment in the government bonds cannot be considered as the least risky due to unstable political and economic situation, constant changes of the legislation and underdeveloped market environment.

Therefore, it is reasonable to use rate of return from investment in alternative assets selected by other criteria as basic rate of return. These may be assets which are the most 
accessible and require minimum management from investor. Deposits are such assets. Nominal rate of return of deposits in freely convertible currency for legal entities in leading Ukrainian commercial banks varies from $6 \%$ to $12 \%$ per annum depending on terms and amount of deposits. Annual average rate of return should be selected as basic rate, which is in line with amount of investments related to capital investments for maintaining the ecosystem functioning and ecosystem services provision.

Classification of the ecosystems of Ukraine, the ecosystem services provided by them, cost estimate of the ecosystem services are in the process of formation. In order to introduce the ecosystem services concept in the management system of ecological safety of territorial units it is necessary to scientifically substantiate, improve and generalise research vocabulary, classification of ecosystems and their services, methods of ecosystems state evaluation and ecosystem services cost estimate calculation, as well as to develop and adopt corresponding laws and regulations.

\section{CONCLUSIONS}

Goals of management of ecological safety of territorial units are as follows:

1) preservation of the natural ecosystems and course of natural processes in them; 2) restoration of primary plant communities and fauna associations; 3) construction of territorial complexes close to natural ecosystems typical for certain physicogeographical zone in anthropogenically modified ecosystems (agroecosystems); 4) preservation and restoration of biotic and landscape diversity; 5) formation of regional and local ecological networks.

2) Implementation of the ecosystem services concept has an important role in the management system of ecological safety of territorial units. The ecosystem approach should be introduced in territorial management by 2020 . Ukrainian legislation should be harmonized with European.

3) Monetary evaluation of the ecosystem services, development and introduction of payment mechanisms and use of costs for these services will allow implementing programs (measures) for ensuring environmentally safe functioning of ecosystems within the territorial units.

4) Classification of the ecosystems of Ukraine, the ecosystem services provided by them, cost estimate of the ecosystem services are in the process of formation. In order to introduce the ecosystem services concept in the management system of ecological safety of territorial units it is necessary to scientifically substantiate, improve and generalise research vocabulary, classification of ecosystems and their services, methods of ecosystems state evaluation and ecosystem services cost estimate calculation, as well as to develop and adopt corresponding laws and regulations.

\section{REFERENCES}

11] M. M. Prykhodko, "Floods and their management in the Carpathian region of Ukraine", Scientific bulletin of National Mining University, vol. 2, pp.113-117, 2017. [Online]. Available: http://www.nvngu.in.ua/index.php/uk/component/jdownloads/finish/6 7-02/8627-02-2017-prykhodko/0. [in Ukrainian].

[2] M. M. Prykhodko, V. V. Romaniuk, D. V. Kukhtar, I. L. Bodnaruk, and N. L. Khmil, "Application of the geographic information system technologies in the geosystem planning process", Geoinformatics, Kiev, Ukraine, pp.5, 2019. [in Ukrainian]. doi:10.3997/2214-4609.201902041.

[3] Ye.V. Mishenin, and N. V. Dehtiar, "Economics of ecosystem services: theoretical and methodological fundamentals", Marketing and management of innovations, vol. 2, pp. 243-257, 2015. [in Ukrainian]

[4] S. A. Smirnov, "A strategy for the sustainable development of specially protected natural areas", University newspaper. State University of Management (Moscow), vol. 20, pp.164-168, 2013. [in Russian].

[5] V. I. Danilov-Danil'yan, K. S. Losev, and I. E. Reyf, "Sustainable Development and the Limitation of Growth: Future Prospects for World Civilization", 2009. [in Ukrainian].

[6] L. A.Wainger, and M. J. Mazzotta, "Realizing the Potential of Ecosystem Services: A Framework for Relating Ecological Changes to Economic Benefits", Environmental Management, vol.48, pp. 710733, 2011. doi:10.1007/s00267-011-9726-0

[7] A. Renaud, "The controller's role in environmental management control", Comptabilité - Contrôle - Audit, vol. 20,(2), pp. 67-94, 2014. doi:10.3917/cca.202.0067.

[8] M. D. Balji, "Organizational and economic principles of the complex nature management at the regional level", Monograph, Odessa, Ukraine: Atlanta, 2010, p.500. [in Ukrainian].

[9] J. Morelli, "Environmental Sustainability: A Definition for Environmental Professionals," Journal of Environmental Sustainability, vol. 1, 2011. doi: 10.14448/jes.01.0002.

[10] A. A.Obikhod, and O. P. Ambrosenko, "Evaluation methodology for competitive ecological potential in the context of ensuring ecological safety of Ukraine", Actual Problems of Economics, 179 (5), pp. 229240, 2016. [in Ukrainian].

[11] M. Nin, A. Soutullo, L. Rodríguez-Gallego, and E. Di Minin, "Ecosystem services-based land planning for environmental impact avoidance", Ecosystem Services, vol. 17, pp. 172-184, 2016. doi:10.1016/j.ecoser.2015.12.009.

[12] R. Adner, "Ecosystem as Structure: An Actionable Construct for Strategy", Journal of Management, vol. 43(1), pp.39-58, 2017.

[13] Objectives of millennium development of Ukraine: 2000-2015. 2015. [Online]. Available: http://un.org.ua/images/stories/docs/2015 _MDGs_Ukraine_Report_ukr.pdf. [in Ukrainian].

[14] C. E. Davies, D. Moss, and M. Hill, "EUNIS habitat classification. Report to the european topic centre on nature protection and biodiversity", Paris for European Environment Agency, 2004.

[15] T.Brown, J. Bergstrom and J. Loomis, "Ecosystem Goods and Services: Definition, Valuation and Provision", Natural Resources, vol. 47, pp. 329-369, 2007.

[16] R. Tinch, N. Beaumont and T. Sunderland, "Economic valuation of ecosystem goods and services: a review for decision makers', Journal of Environmental Economics and Policy, 2019. doi: 10.1080/21606544.2019.1623083.

[17] Ecosystem services of Russia: Prototype of the national report. Terrestrial ecosystem services, vol. 1, 2016. [in Russian].

[18] R. H. Haines-Young, and M. B. Potschin, "Common International Classification of Ecosystem Services (CICES) V5.1 and Guidance on the Application of the Revised Structure", Fabis Consulting Ltd, 2018. [Online]. Available: https://cices.eu/content/uploads/sites /8/2018/01/Guidance-V51-01012018. pdf.

[19] A. John, and all, "Economic Analysis of the Environmental Impacts of Development Projects", Earthcan Library Collection. London, p.148, 2013.

[20] Ya.S Vytvytskyi, "Economic evaluation of the oil and gas companies mining capital", Scientific monograph, Ivano-Frankivsk, Ukraine: IFNTUNH, 2007, p. 431. [in Ukrainian] 